Society and Economy 31 (2009) 1, pp. 125-146

DOI: $10.1556 /$ SocEc.31.2009.1.8

\title{
EDUCATION 2.0: EXPLORING THE CHALLENGES OF CORVINUS UNIVERSITY IN THE LONG TAIL ECONOMY OF GLOBAL HIGHER EDUCATION
}

\author{
SÁNDOR KEREKES* - ANDRÁS NEMESLAKI** \\ *Vice-Rector, Corvinus University of Budapest.E-mail: sandor.kerekes@uni-corvinus.hu \\ **Vice-Dean, Faculty of Business Administration, Corvinus University of Budapest. \\ E-mail: andras.nemeslaki@uni-corvinus.hu
}

\begin{abstract}
Our basic storyline is how the business and economics higher education landscape has changed with the introduction of the Bologna programs. We borrowed the fashionable long tail concept from e-business, and used it for modeling the new landscape of internationalization of universities. Internationalization, mobility, and the appearance of the internet generation at the gates of our universities in our opinion has brought us to a new e-era which, appropriately to our web analogies we might as well call Education 2.0.

In our paper first we show the characteristics of the long tail model of the Bologna-based European higher education and potential messages for strategy making in this environment. We illustrate that benchmarking university strategies situated in the head of the long tail model will not always provide strategic guidance for universities sitting in the tail. For underlining some key concerns in the Hungarian niche, we used Corvinus University as a case study to illustrate some untapped challenges of the Hungarian Bologna reform. We explored three areas which are crucial elements of the "tail" strategy in our opinion a) the influence of state regulation, b) social situations and impacts and c) internal university capabilities.
\end{abstract}

Keywords: Corvinus University of Budapest, Hungarian higher education, Bologna reform, educational strategy, university capabilities, social challenges, long tail business model

\section{INTRODUCTION}

In 2004, Chris Anderson, the chief editor of Wired magazine, has published a seminal article about the "Long Tail" which has become one of the most cited references of the internet economy in recent years and a key element of the popular Web 2.0 concept (Anderson 2004). Anderson's original example was music and as we show in Figure 1, he argued that the distribution of products in this industry 


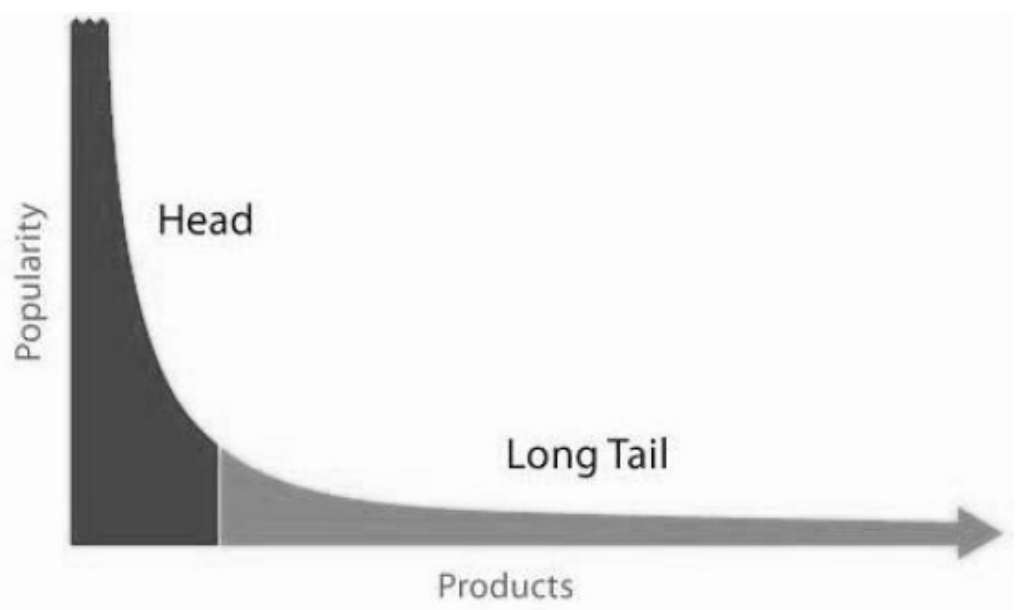

Figure 1. The Long Tail model

has two distinct parts: the head of the distribution curve and the tail each having different features.

Products in the head are popular, available in large volumes, producers can achieve scale of production, lower unit costs. Distributors' attention is focused on these items, profitability can be achieved with relatively low risk. Products in the tail, however, are less popular, serve more unique demand, volumes are lower, profitability can only be achieved with targeting, focus strategies, personalization and tailoring. As Anderson argues the essence of the long tail philosophy is that in the internet economy unlimited choice rules the markets, especially in the case of digitized products. In this environment not only those businesses can prosper who provide critical mass and large market share but also those who produce tailored, personalized, niche products. Companies operating in the tail are also just a "mouse click away" from customers, and they can be found as well with smart search engines, carefully selected keywords, as easily as the big players in the head. Tail products certainly might provide very high business value and unique selling proposition (USP). Though it might sound strange at first, we believe that the Bologna reform of European higher education has created a long tail phenomenon in the education market and using the internet based analogy we are able to look at this market through an interesting lens. Internationalization, mobility, and the appearance of the internet generation at the gates of our universities has brought us to the era which, appropriately we might call Education 2.0.

We would like to clarify, that the objective of this paper is not to develop arguments pro and con for the debated long tail model. We are aware that the 20/80 rules of Pareto principle has been around, or the theory of "scale independent networks" can be described with binominal distribution which is not a scientific nov- 
elty in the management literature. We do not want to criticize the originality and novelty of the long tail concept neither to fall into an unbiased admiration of it as the latest management fad. Rather, we have chosen the long tail model because its logic nicely illustrates the concept of "niche" in the "globalized" higher education industry.

In our paper, we first show the characteristics of the long tail model of the Bologna based European higher education, and summarize some potential messages

for strategy making in this environment. Then we will use Corvinus University of Budapest (CUB) as case study to illustrate some untapped challenges of the Hungarian Bologna reform to show the usage of the long tail concept for a systematic analysis. The Bologna reform potentially redraws the competitive map of the management education market; provides opportunities to new players and serious threat to "brand" institutions. Presently, CUB's business programs are all ranked amongst the best 3 in Hungary and its pre-bologna M.Sc. in Business Administration is the only internationally ranked Hungarian program in management (Financial Times Master of Science in Management Rankings 2005, 2006, 2007). The real strategic question how this can be maintained and improved.

\section{THE LONG TAIL MODEL OF INTERNATIONALIZATION: HIGHER EDUCATION 2.0}

One of the key ideas behind the Bologna Declaration was to increase mobility in European higher education. Using the long tail model, our starting argument is that universities in the head of the educational markets have a great advantage over universities situated in the tail. This logic exists in the domestic markets when we explore regional mobility and in global markets in the case of international mobility.

Based on our observation of rankings, peer opinions, brand image, in Figure 2 we have created a conceptual long tail model for illustrative purposes.

The classification of higher education institutions in business and management regarding their internationalization is very complex. Rankings, accreditation bodies have sophisticated measures including mobility numbers, ratio of foreign and domestic students, faculty research in international publications, faculty composition, international business projects and several others. Since we are not aware of such analysis, we used the Financial Times aggregate ranking of European Business Schools, and weighed the ranks with graduate performance (salaries, promotion) to characterize the strong asymmetry between schools (Financial Times 2009). This is plotted in the dotted line which we then simplified with the solid long tail trend line. 


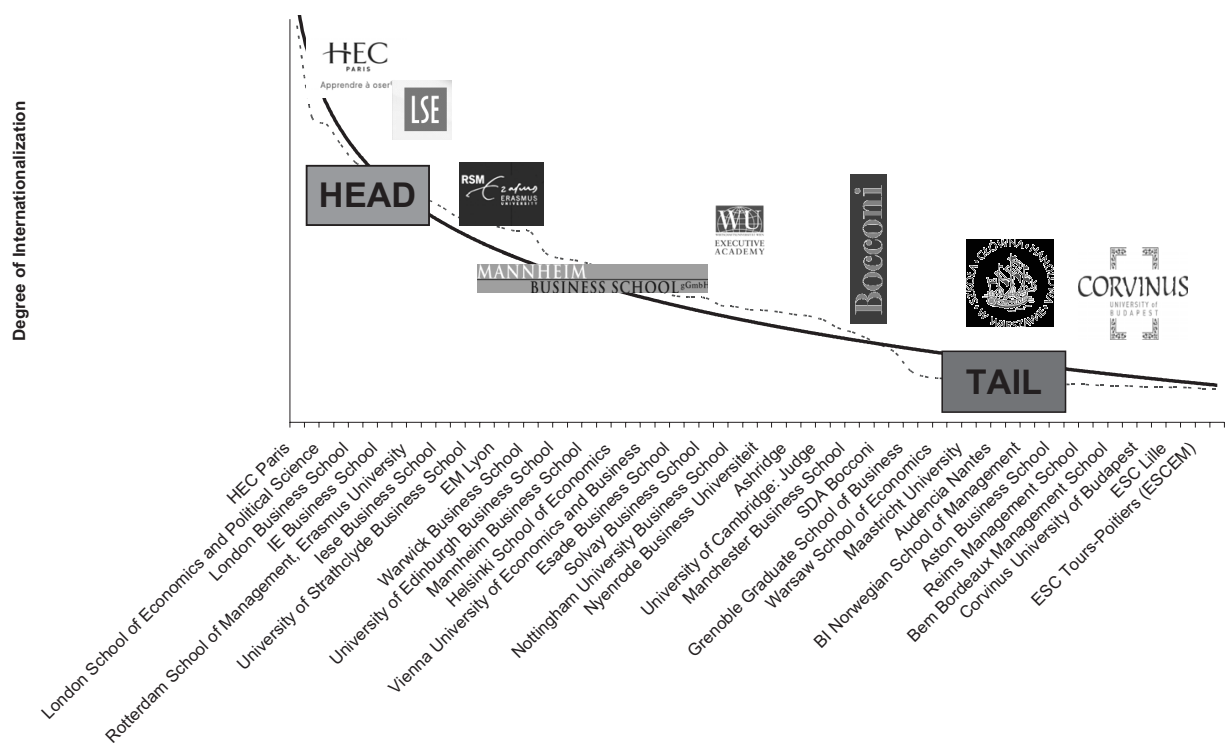

Figure 2. Education 2.0: the long tail model of international business education (based on the Financial Times European Business School Ranking)

In Table 1 we summarized some of those characteristics which we believe determine if a school is situated in a tail or the head. Some of these are obviously indicative in the rankings, however, some are more subtle and do not appear directly in published rankings.

Table 1. Characteristics of the head and tail institutions in education 2.0

\begin{tabular}{lll}
\hline & Schools in the head & Schools in the tail \\
\hline $\begin{array}{l}\text { Culture } \\
\text { Language }\end{array}$ & Asian/Latin American/Anglo saxon & $\begin{array}{l}\text { Scandinavia, CEE } \\
\text { Resources }\end{array}$ \\
Role in globalizh, Spanish, French, German & $\begin{array}{l}\text { Danish. Polish, Hungarian } \\
\text { Private, state, donations, extensive } \\
\text { Famous brands, historical heritage } \\
\text { (Dutch, Swiss, Italian) }\end{array}$ & $\begin{array}{l}\text { International brands are } \\
\text { rare, closed, less inter- } \\
\text { nationally known history }\end{array}$ \\
& Extensive off-shoring & $\begin{array}{l}\text { Distant from knowledge } \\
\text { development, or only }\end{array}$ \\
Corporate headquerters & flose to corporate HQs, strategic & Accreditation is local, \\
level impact & Accreditation is designed in this & difficult to match criteria \\
\hline Accreditation & paradigm & FOCUSED STRATEGY \\
\hline CONSEQUENCE & BROAD STRATEGY &
\end{tabular}


Language and culture at a broad sense are key determinants of mobility and internationalization in the Bologna system. Therefore those destinations and schools which are closely related to the mainstream big languages or dominating cultures of the present and near future will be always in the head, and in potentially dominating positions of globalization (in our charts these are HEC, LSE, LBS and IESE). Connected to this, there are some premium institutions either equipped with vast financial resources through their alumni, tuition base and sometime state contribution as well. Their brand and historical heritage also predestines them to become head schools even if they are not directly tied to dominating languages and cultures. A typical example for this is the IMD School in Lausanne, which is one of the leading business schools in the world especially in executive development. The third factor of long lasting head presence is being close to the globalizing industry and corporate relations. For this reason schools which are in the proximity of corporate headquarters, innovation centers where the application of knowledge and research is happening are also potentially in good position. Finally, we have to emphasize that mainstream accreditation regimes (AACSB, EQUIS, EPAS, AMBA) base a lot of the criteria on the experience of head which makes it very difficult for tail schools to meet them. Most schools in the head of Figure 2 were pioneers in getting EQUIS accreditation for instance and consequently their leadership is always shaping the criteria and more established in assessing results of achievements.

What we experience in the head, almost the opposite can be conceptualized in tail. Schools here are in less dominating cultures and languages, farther located from corporate headquarters, their funding is more limited and the brand value is less solid. Corvinus University of Budapest is a "tail" school from many respects in the European and international context, but we can also see other Central Eastern European schools and less mainstream Dutch or British universities.

The conceptual principle based on which we would like to discuss the main challenges of CUB is that the transfer to the Bologna Educational System has emphasized the long tail phenomenon in European higher education. The key issue in the tail is: niche. Understanding, focusing and managing the niche is the principle, based on which successful strategies can be developed in the global arena of higher education. Furthermore, the pragmatic analysis of the specific characteristics, limiting factors and opportunities is also very important in our opinion. In this paper we would like to present some less frequently quoted issues of the Bologna Reform in Hungary and in the case of Corvinus University, which are illustrations of such niche factors.

It is always encouraging to witness, that Hungary has an incredible historical reputation in tearing down the totalitarian regimes in Europe starting in 1956 going all the way to letting the East German refugees through the western borders in 
the summer of 1989. It might sound strange, but all this sentiment has contributed greatly to the internationalization of our economics and business higher education theatre in the early 90s. Most universities came to us, we could operate in a comfort zone, almost everything was interesting what happened in Hungary. Our USP was self explanatory: the transition of CEE. During that time it was acceptable that the penetration of English and other languages was not very high, that research outputs were very rare according to international standards and quality of education was quite spotty. For the millennium generation these times, especially 1989 and before are history, it is granted that CEE is part of the EU, crossing borders is seamless just like transferring credits from one place to another. The external reviews cruelly show the mirror of change and the evidence that Hungary's higher education is in a different era. Consequently, living only on past achievements will not contribute to the advancement of international recognition and acceptance.

During the last couple of years we have started the ongoing international outside reviews of our programs and systems. The first was in 2004 the CEMS MIM peer review, then in 2008 the European University Association visit and EQUIS eligibility review and at the time of the preparation of this paper an EFMD EPAS program accreditation review. As a consequence of these we face several criticism regarding our governance structures, faculty policy in teaching and research, with regards to the teaching methods, innovativeness, quality regimes, the lack of strategic coherence amongst different units and very importantly our degree of internationalization.

Most of the above reviews made it clear that Corvinus University cannot carry on its international strategy on the paradigm of the last 20 years. To simplify the situation the main reasons can be summarized as follows:

Central and Eastern Europe is not as attractive a region as it used to be after the Berlin Wall came down. Especially, from the break out of the 2008 crises the CEE countries all face serious economic decline, financial crises and political struggles which have serious impacts on their international performances. FDI to the region has slowed down, the golden years of the mid 1990s have come to an end. International companies have established their operations, and external support grants (eg. USAID) do not pour money into education and development any more.

The demand of the regional labor market has also transferred. The market transition period after 1989 was characterized by large scale privatization and a dynamic expansion of the Hungarian economy. For business and management positions this process basically meant that between 1995 and 2001 was an enormous demand for graduates with a fresh knowledge of finance, marketing, management, human resources. At Corvinus we were hardly able to produce enough supply; in this time period 1 student got $7-9$ job offers on average. By now, the ex- 
pansion of the economy has closed, and the state reforms for Euro convergence took the priority, the management market became saturated, most recently on average there are 3-4 applicants to one offer in these areas.

Competition among schools, programs, universities has been intensified tremendously, especially driven by the fact that demand is decreasing both in student numbers and availability in financial resources. The Bologna Reform in the Hungarian higher education is fully on the move, in 2009/10 the last traditional, 5 year long business and economics programs will release their students and the new bachelor-master programs will be fully operational.

The first generation of the post-soviet era has arrived to doors of our universities. It is interesting and challenging not only from the point of view that they were born in new democracies, but they are also often referred to as the "internet generation" for whom the information society is not a communication revolution but a fact of life. New marketing techniques, new type of academic image creation is essential to reach out for talented students, and we have to be aware that the "competition is just a click away" for them as well.

Probably the list could be continued with several other indicators which basically all say that the paradigm of the "happiest camp in the communist bloc" and the "demolisher of the Iron Curtain" is over. Not only Hungary has to be re-invented from this point of view but very specifically the Hungarian economics and business higher education as well, USPs have to be developed both in education and research.

At the same time, the logic of the "tail" strategy suggest that accepting all the rules and suggestions from mainstream international establishments might be risky for business and economics higher education. If nothing else, the 2008 world crises demonstrates clearly, that accepting all trends without critics and doubt might lead to such bubble effects which we have experienced in the financial markets. Without providing a full list, we point out some unique elements of Corvinus's "tail" strategy principles.

First, we cannot give up original research and nurturing of talents, and should be able to offer competitive master and Ph.D. programs, which keep a significant body of talented students in Hungary, no matter how attractive a "feeding" school status might be. Secondly, internationalization for us in the Carpatian Basin also has a special meaning; providing opportunities for Hungarians not living in Hungary to continue their studies in Hungarian and be able to mix and preserve their minority culture effectively with their home countries in Romania, Slovakia, Ukraine, Serbia, Slovenia, Croatia and Austria. Thirdly, we have to be aware that Hungarian is a very unique language and Hungarian culture is not a mainstream global touristic destination. Several small nations have similar problems like Denmark, Finland or the other Central Eastern European countries. However, most of 
them have historical, language or cultural relations to one other European or overseas nation (Portugal, Brazil for instance, or Slavic cultures to each other), while Hungarian is a rather isolated culture globally. From this respect, one has to understand that the Hungarian nation for centuries has justified itself by the Hungarian language, which still explains why foreign language knowledge is not as widely spread as in the Scandinavian or Dutch culture for instance.

In the next sections we will discuss three areas which are crucial elements of the "tail" strategy in our opinion using the case of Corvinus University but being convinced that the three topics: a) state regulation, b) social situations and impacts and c) internal capabilities can be extended to other similar universities as well.

\section{CORVINUS IS DETERMINED BY STATE REGULATION}

The Bologna process started close to 10 years ago in a very different higher educational environment. For instance, in the period of 1998-2007 a dramatic expansion of higher education has happened mainly in the areas of business and law; the number of students has increased from $15-20 \%$ to $40-50 \%$, also at the same time employment rate in the age group of 20-24 years old individuals has decreased from $54 \%$ to $38 \%$ indicating later entry to the labor market in this age group.

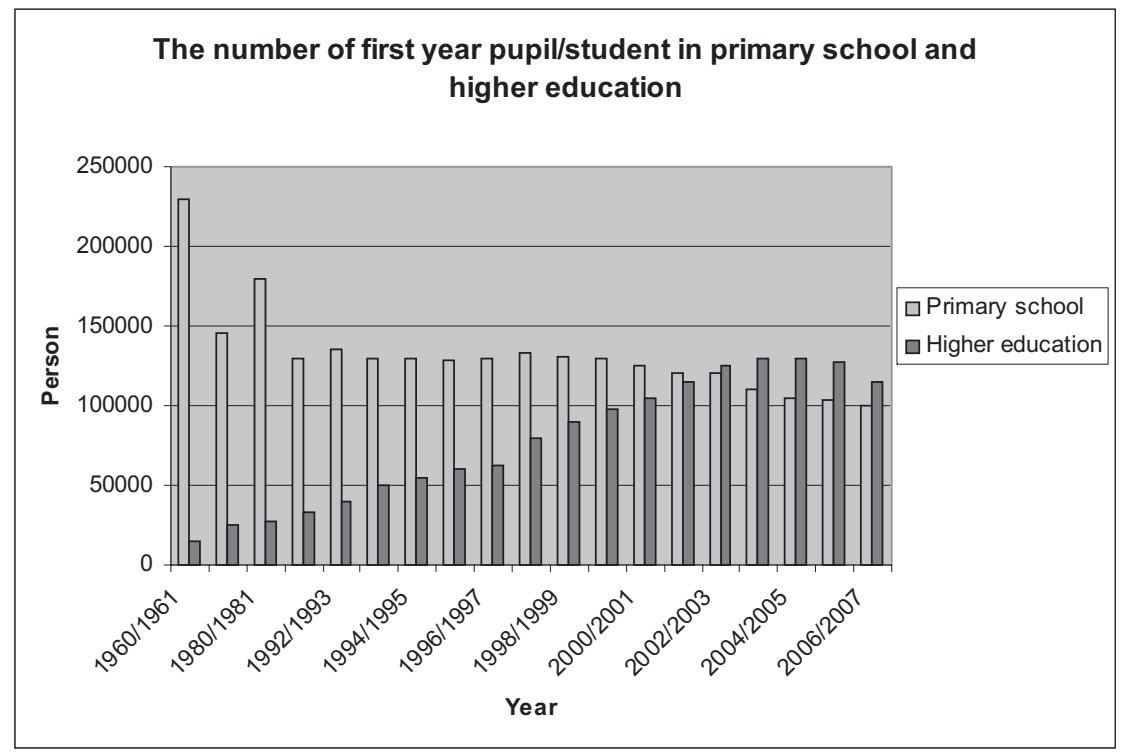

Figure 3. Number of freshmen in primary school and universities 
This expansion of the higher education "industry" is shown in Figure 3. No matter how promising the growth was, the other trend has indicated that domestic intake will not provide supply on the long run, since the number of first grade students has been gradually decreasing. This is an unfortunate demographic issue, and as Figure 3 illustrates the number of students intake into first grade is less then the college level intake since 2002/2003.

This shrinking domestic market is served by 71 accredited higher education institutions. In 1989, as a comparison before the political system was changed, there were 57 . The increase was driven mainly by the entrance of church institutions, and also 14 private colleges and universities were founded. These market players are very small (less than 1000 students), so state owned establishments have kept dominating the market. Their numbers have decreased by 2000 from 59 to 31 while student numbers have increased (there are 10 universities and colleges in the country where student number exceeds 10,000).

There are two kinds of traditional institutions: universities and non-university status colleges. Universities focused on theoretically based education with 4-5 years of minimum studies. They have been entitled to issue graduate, post-graduate and Ph.D. degrees. Colleges, on the other hand, are focusing on professional skills and training, techniques and tools. Studies lasts three-four years and they have provided "undergraduate" degrees. This system basically solved the problem of providing generalists (universities) and specialists (colleges) for the Hungarian labor market (Hrubos 2006).

The latest version of the Higher Education Act accepted in 2005 creating the regulatory framework for the Bologna based reform of the Hungarian higher education, stated that only Ph.D. programs remain in the university domain exclusively, and authorized both universities and colleges to submit bachelor and master programs for accreditation upon their own decisions. This way the Hungarian state basically opened up the competition on the undergraduate and graduate market.

Before the financial crises arrived to Hungary, its GDP growth had been one of the slowest in the CEE region, with an inflation rate around 6-8\%, and the budget deficit in 2006 was 10\% (almost three time higher then the Maastricht criteria allows). Hungary's macroeconomic policy is determined by the Euro convergence which creates budget pressures, low economic growth, and high political instability.

The climax of the political tensions around higher education was during the fall of 2007 when a public referendum erased the intention of the government to introduce mandatory tuition fees in higher education. The objective was not only to expand the funding sources but also to provide economic incentives to students and parents to act more as "clients" of educational services rather then taking it as a 
"free" state benefit. Payment is not alien to the Hungarian higher education, close to 50 percent of full time first degree students pay contributions to their studies not even mentioning the part time and continuing program participants. Still, the term "tuition" is considered as a red canvas, and can determine election votes therefore both political leading parties treat it as an untouchable issue.

Another political challenge is how the government sets and enforces higher education strategies. Majority of universities are state owned and funded so there are some political agendas transferred through colleges and universities. For instance, local governments have strong political and lobby power to keep educational institutions even in the less populated areas, since these serve as key cultural an intellectual hubs. They make much effort to reverse the trend of program concentrations in Budapest or other big cities in order to prevent the loss of their local "university" culture, even if both from an economic and quality point of view the operation of these establishment is questionable. In business and economics it is especially relevant, because of the low entry barriers of these programs, regardless of the fact that there is no local graduate market.

Spreading funds evenly for higher educational institutions serves lots of admirable goals, but at Corvinus we also see that there is a need for a recognized differentiation between some really high quality premium universities mainly for the sake of international competition. As we pointed out earlier Hungary is too small, and too "alternative" a destination (language, culture and history) to allow its universities to compete alone in a resource intensive and highly demanding global competitive environment. To determine key foci, and directions some hard decisions should be made about the principles of differentiation and later for providing special funds to the selected few institutions.

Politically this is a difficult task because of the consensus seeking nature of such strategy processes. The key preparatory gremium of higher education is the Rectors' Conference where all institutions, Student Government and authorities are represented. Given the highly political nature of such a conference most decisions have to reach a common denominator which only allows little playfield in setting priorities for development, or they are so broad that they do not allow real institutional differentiation.

Let us take a look at state policy first and how it influences CUB strategy.

The first mechanism of state influence is of course funding. The Hungarian state provides funding for state owned higher education for three main activities: a) for research and scholarship, b) for maintaining university assets such as buildings and c) to provide education for students in preferred disciplines. Research is recognized and financed by providing contribution based on the number of faculty owning Ph.D.s, asset maintenance is basically motivating management to uti- 
lize the facilities effectively, but the most influential to the strategy of a university is the financing provided for the students.

In this respect, the state acts as the key customer of the Hungarian higher education industry by setting the number it is willing to enroll in any given year in any given discipline. For instance in 2008/2009 in the discipline of business and economics the state finances 5900 places. In general, preference is in engineering and natural sciences given employers demand and the Hungarian industry structure (9400 places in engineering, 4100 in natural sciences and 4700 in computer-information sciences). Liberal arts and law are gradually decreasing, they are less in focus for state support - 4800 places in liberal arts for instance in 2008. It has also become clear that state funding of students on the master level will be about one third of the bachelor level in order to motivate bachelor graduates for mobility and for entering the job market in much higher numbers then presently.

The second very important control for the higher education institutions is institutional and program accreditations. In 1993 the Hungarian Accreditation Committee (HAC) was formed to ensure that educational institutions deliver programs which meet academic quality requirements. Accreditation procedure is required for all types of higher education institutions and programs. The accreditation criteria of the Hungarian Accreditation Committee puts the requirements forward that each institution should have all the required resources (professors, facilities, corporate relations, etc.), and based on this a so called "institutional capacity" the maximum number of students is determined.

During the last couple of years it has also become recognized that not only the state can act as a "customer" but also students themselves contribute to their education. Therefore even the state institutions can offer so called cost-reimbursement enrollment places. For the sake of simplicity in the following we call this tuition payment, but conceptually the fees are fraction of the real education expenditures. 50\% of Corvinus' income is of non-state origin, in some programs and disciplines (like in the MBA program for instance) can be close to $100 \%$. Consequently, strategic maneuvering is fairly clear: universities can develop "capacities" either for state supported students or for cost reimbursement and then they have to build up marketing actions to generate enrollment accordingly.

This leads us to the third key state mechanism which is the admission process or in other words how the capacities are filled up in higher educational institutions. At the bachelor level admission is centralized, basically applicants are ranked according to high school results, language exams, and other academic performance. Capacity is filled up based on applicants' preference and aggregate high school performance, through a totally automated process until the state quotas are exceeded. In principle, this method provides a market selection: universities with large number of high performance students easily fill up their programs 
and also get quality "input". Institutions with low number of applicants or too many with lower level high school results often cannot reach capacity and their student population is of a much wider quality range. Actually, quality might even vary within institutions since performance thresholds for admission are set discipline by discipline or program by program. For instance at Corvinus the BA in International Business is always started with full capacity, with students who have top admission points. Finance and Accounting which is historically one of our strongest programs is also full capacity but with at least $10-20 \%$ lower admission point average.

The fourth guiding factor is how the programs offered are controlled. Government has tried to avoid the overabundance of "institutional" programs and specializations by enforcing the market players to agree on "minimum" requirements and a universal/transferable country wide educational portfolio. This objective has been achieved by creating two consortia - one for the bachelor programs and one for the master programs - consisting of representatives of all the main higher educational institutions and they have agreed to create and submit joint accreditation materials to HAC. Consequently, a transparent nation wide structure has been created and individual institutions could decide a) which programs they want to prepare for institutional accreditation (capacities, faculty, etc.) and b) which program they want to market and launch once the accreditation has been awarded.

Consequently, the new landscape of business and economics education has dramatically changed in Hungary. First of all a relatively large number of programs have been accepted by the two consortia and submitted for accreditation. One could say this is quite natural, since major compromises had to be reached; every institution was lobbying for their disciplines to make sure that they are in the accreditation package. The bachelor consortium has been dominated by the colleges, given their experience in the full fledged undergraduate degree delivery, therefore several new conditions were included, which universities had to develop in order to catch up (internship programs on the mass scale, the inclusion of skill development for undergraduate levels etc.). The master consortium on the other hand was only organized for universities since colleges had no experience on this level. Presently in the disciplines of business and economics there are 10 B.A. and 13 M.A. programs summarized in Table 2.

The positive side of the consortial work has been the clear transparent offering of programs for the students and the labor market, the negative side is that there is no room for product differentiation: competitive advantages cannot be achieved based on program profile. At Corvinus for instance we have built up a huge bachelor capacity, since the university strategically decided to launch all B.A. programs given the history, experience and the strong effect of the school's brand. Also, as we described earlier, the state funding structure clearly indicated that financially 
Table 2. Accredited programs in business and economics

\begin{tabular}{lll}
\hline & Accredited Bachelor and Master programmes in business and economics \\
\hline Discipline & Bachelor programme & Master programme \\
\hline Business & Management and Business Administration & Management and Leadership \\
& International Business & Marketing \\
& Commerce and Marketing & MBA \\
& Finance and Accounting & Accounting \\
& Tourism and Catering & Regional and Environmental \\
& & Economic Studies \\
& Human Resource Administration & Business Development \\
& Vocational instruction in business & Tourism Management \\
\hline Economics & Applied Economics & Quantitative Economics \\
& Economics & Economics \\
& Public Governance & International Economics and \\
& & Business \\
& & Finance \\
& & Public Policy and Management \\
& & Acturial and Financial Mathematics \\
\hline
\end{tabular}

much more stabile revenues can be collected on the first level than on the master and $\mathrm{Ph} . \mathrm{D}$. This created the challenge of moving into areas which have been traditionally not core expertise at CUB and also developing competencies in the areas of training, skill based education and internship capabilities.

The challenging side of the new era is how to cope with this incredible fragmentation both in terms of quality and in terms of efficient program delivery. On the bachelor level the difference between the traditional universities and colleges have disappeared, and thanks to the low entry barrier there are close to 200 business and management programs offered in Hungary. Since institutions do not differ any more in their products (same program portfolio at most big players) strategically differentiation should be developed on other factors such as branding, internationalization, service, marketing, corporate relations, and placement.

Preserving and improving institutional profile is a key success factor, especially internationally. We, for instance, find the Corvinus brand very strong, but it is important to realize on what characteristics it had been built. In economics and management our institution was known about its solid micro and macro economic disciplines, the depth and breath of quantitative techniques (statistics, mathematics and operations research). All the specializations from finance to marketing and from accounting to management control were building on the solid knowledge of students on these foundations. Employers have known, Ph.D. program directors and also partner institutions knew when working with Corvinus in Budapest, these are the key value elements one might expect from the programs in general. This profile we intend to keep and strengthen, therefore students take most of the 
foundation courses together regardless of their programs or specialization. Naturally, new characteristics have to be developed and strengthend, for instance the practical skills in the bachelor level, or the alternative teaching and learning methods such as cases, group projects and internship based assignments.

\section{SOCIAL CHALLENGES: IMPLICATIONS FOR MOBILITY}

In this section we would like to show some social and market consequences of the Hungarian Bologna transfer which are less visible, but in our opinion timely and effective responses to them might determine the competitive situation of higher educational institutions. One of the key objectives of the Bologna educational system has been to enhance mobility within the European "educational space" in order to enhance diversity which is a crucial factor to make European higher education more competitive globally. This is essential to accommodate the needs of the labor market and the growing internationalization trends. From Hungary's point of view this is both a great opportunity and a main challenge for education and regional development.

The fact that students can change the place of their bachelor and master institutions easier than before might make the system socially more acceptable in Hungary. Namely, at the moment there is a relatively low number of students using the possibilities of Erasmus mobility in Corvinus (around 15\% in case of the Faculty of Business Administration) but when we asked the students in the bachelor programs close to one third of them indicated their intention to continue in another higher education institute - preferably somewhere outside of Hungary. Who are these individuals? Probably, the financially better off, also maybe the more talented and ambitious. We also noticed that interest towards the exchange programs starts already in the early bachelor years, students are seeking international exposure already after the second year of their study. They see this as a potential to increase their competitiveness and do not seem to wait for the master years which we kind of anticipated. While this is certainly a very favorable tendency for globalizing our students, the question remains how our programs will look like if we cannot keep talented and motivated, high quality students, or at least some of them. This is the international "brain drain" challenge for Corvinus, which clearly forces us to enhance our international capabilities paradoxically both for maintaining our national leading role and to attract foreign talents.

Apart from international mobility, in our opinion the bologna reform will create a major threat to some domestic regions in Hungary. Hungarian rural structure is rather fragmented, even the large cities stay in the range of couple hundred thousand inhabitants. The differences in economic development are very large, 
some Western Hungarian regions produce twice or even three times more GDP/capita then some Eastern or North-Eastern ones. Higher educational institutions on the other hand are physically located evenly, some large reputable universities are found in the economically disadvantaged regions. These institutions naturally attract students outside of their region, which is very favorable for local culture and intellectual life. The problem is that upon graduation students leave these regions (Eastern, Northern and Southern) and relocate to the Central (Budapest) area or Western Hungarian cities. We believe the regional and rural Hungarian markets therefore face a severe social challenge, that is students finishing their bachelor program in rural Hungary might come to Budapest to a "national" university to continue their masters. This trend, which we might call domestic brain-drain, will be favorable for those universities which will be able to strengthen their brand, reputation, and ties with the business community.

Not only the unfavorable demographics and fragmented rural structure, but also the slow change in the job market suggests that capabilities to count with large scale mass undergraduate and graduate educational markets - especially in business - will be limited.

Corvinus is standing solid in national competition but the over-production of business graduates and the difficulty of getting professionally interesting and well paying jobs will create lots of disappointment in the next couple of years. The new drivers of growth and demand for education are in engineering, information technology and other natural science fields; in 2007 industrial growth was almost 8\% to compare with the whole economy which was crawling with $1-2 \%$, just to quote one macroeconomic indicator for illustration.

The second change in the job market which, in our opinion, higher education should recognize in Hungary is the growing significance of small and medium size companies (SMEs). In $200599.2 \%$ of registered businesses had less then 50 employees, and only $0.1 \%$ employed more then 250 people. Although it is true, that these companies produce $75 \%$ of Hungary's industrial production and $80 \%$ of its export, yet SMEs' production grew 8\% in 2007 indicating that this segment is gradually playing a key role in Hungary's economic growth. Up until recently universities designed their programs and program portfolios to satisfy the "big players" demands, contributing to the extreme specialization of business and management programs. The growing significance of the SME market however, requires more generalists on the job market who are able to solve complex problems in multidisciplinary areas combining knowledge in marketing, finance, strategy and operations. Unfortunately, with the high fragmentation and very early specialization - even at the university entry - students are forced to make decisions which they are not ready for, and at the same time the market does not even require them to do so. 
Corvinus has a solid tradition in providing a unified undergraduate generalist education in economics and business which has enabled graduates to adapt to changing niche needs of the labor market. Formerly students only specialized after the $3^{\text {rd }}$ year of their studies into functional areas such as organizational studies, marketing, environmental management, logistics, entrepreneurship, financial management or accounting. These first 3 years gave enough information to both the students and the faculty to select fields of study according to best interest and talent, not to mention the effective utilization of all teaching resources including faculty time, class rooms, and administration. Due to the pressures of the consortia work (as we described earlier) but also pushed by departmental interest, Corvinus has given up this tradition, at least as it is appearing on the market. From capacity utilization point all the 10 B.A.s basically have the same curriculum in the first two, two and a half years, so this way the general knowledge is maintained somehow, and also the traditional institutional profile is maintained.

We believe that one high risk social impact of the Bologna educational system is the expansion of the family/carrier decision for young graduates. A key cultural and social challenge in Hungary is the aging and decreasing population which we illustrate in Figure 4. With this continuing trend the presently 10 million inhabitants in Hungary will only be around 7.5 million by 2050 , with a higher population in the old age ranges then in the younger ones. The problem is not specific to Hungary, we can state that it is similar in most of Europe.

On a macro level, Hungary should motivate the increase of population both by natural birth and also by immigration. If we further increase the study period of younger generations and prolong the time of adjustment to jobs and work life, we

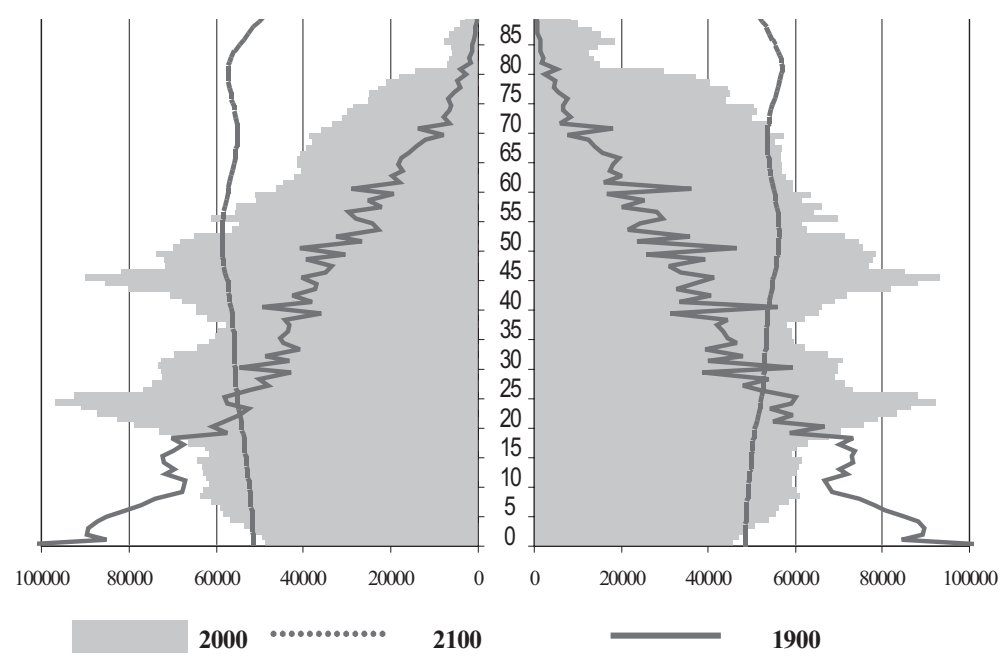

Figure 4. Demographic trees in Hungary 
definitely make it more difficult for younger couples to take on two or more children which could stabilize the natural reproduction. With the separation of the bachelor and master systems and putting years of practice in between the two the carrier/family decision easily moves close to the age of 30-35. The Hungarian Statistical Office already reports that much less women take children during the age of 25-29, but instead the first children are born in the following age group (30-34 years). Naturally, this statistically reduces the willingness and time to raise more then two children which stagnates or further reduces natural reproduction.

\section{CORVINUS CHALLENGES: INTERNAL CAPABILITIES}

Apart from the market and social challenges the Bologna transition creates internal challenges in Hungarian higher education institutions which we labeled as "capability". At Corvinus we identified these as innovation, internationalization and faculty capabilities.

Innovation capability is crucial in the forthcoming era, because applicants and other stakeholders will look at program content elements when making decisions on how to support higher educational institutions.

If we take the master programs for instance, according to the accreditation criteria 120 ECTS "working" material is needed, provided that the different programs have $30-40 \%$ required "distance" - that is difference in content - from each other. This requires a huge effort of material development and program innovation if we consider for instance the 13 different M.A.s in management and business. The key challenge is how to develop and maintain this innovation capability, how to align funds, motivate faculty focus and time, or ensure EU or corporate sources.

It appears that some institutions will not be able to play on the entire scale of the portfolio from this respect. Faculty capacity, state funding access to EU funds is too thin in Hungary to spread it so wide, yet alone considering the high level of specialization as we outlined in section 2. It is also quite clear, even in a leading national institution like Corvinus, that it is unavoidable to consolidate programs somehow. At Corvinus for instance we run both the B.A.s and the M.A.s with more than one third of the courses identical in order to achieve economies of scale, and only differentiate significantly amongst the programs at the final stages of studies.

Innovation type capabilities could be expanded by an effective credit transfer system, that is recognizing course work and equivalents from other programs and universities. Theoretically this works, but as a recent EUA audit showed, few 
ECTS is recognized at Corvinus in core course areas so we should make integrative steps to ensure effective "outsourcing" and recognition from other universities.

When designing new programs, and courses the key objectives according to the reform are supposed to be spelled out in the learning outcomes and competencies. Topics, teaching methods, grading and materials all should be logically derived from and fed back to these outcomes in order to clearly see the value of individual courses and full fledge programs. On top of the pedagogical reasons, the system of learning outcomes/competencies are key determinants of credit transfer decisions and course equivalencies. At Corvinus during this early stage of the program and course design these important objectives are unfortunately mostly seen as administrative burdens for the curriculum outlines. Therefore we intend to put a heavy emphasis on this, course and program development should driven by learning outcomes and to select the best methods to reach them.

Faculty as the most important teaching resource is challenging from several perspectives. We would like to introduce two of these; the first being the age distribution the second the international composition.

In Figure 5 we illustrate the age distribution of our full time faculty at Corvinus, where a clear generation gap can be seen in the age group of 40-50 years. In some regional universities this gap is even deeper. The generation gap implies several challenges including business relationship, research, program management and indoctrination of young faculty.

If we take for instance the business relationship questions, we can see that decision makers in business are exactly in the age group of the "gap", so maintaining contacts, liaising with executives and understanding the rapport and chemistry of

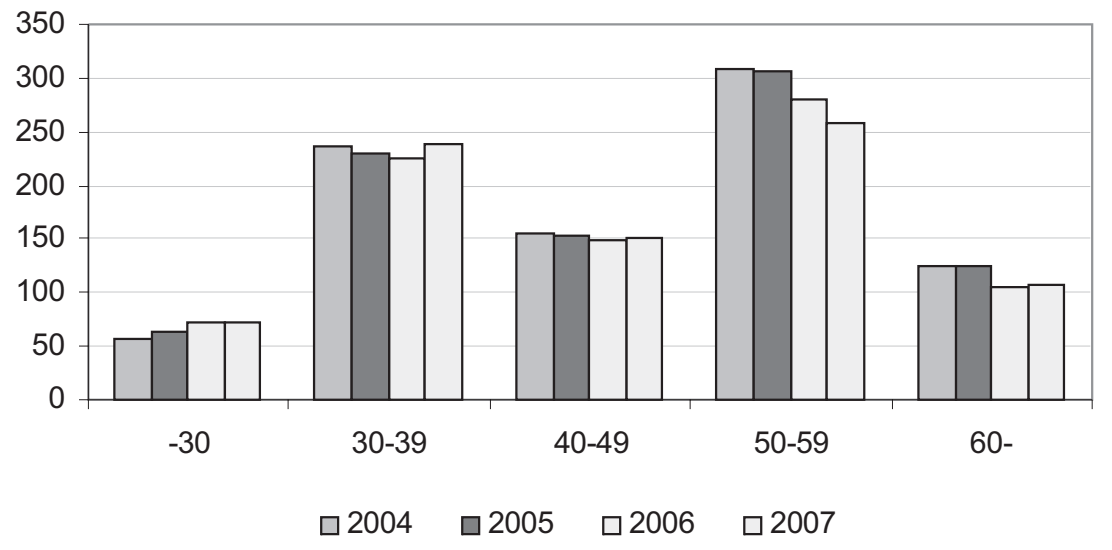

Figure 5. Faculty generation gap in Corvinus 
relationships is not easy: there is a decade difference of university leadership and the current business community in Hungary.

Similar problems arise in the management of younger faculty: life situations and the change in the research and educational paradigm is so huge which makes it quite difficult for the group of 60s to understand the group of 30 and younger in terms of their carrier objectives and conflicts. In program management, given the long cycles of academic development, quite often the results and "raison d'etre" of innovations are connected to individuals who will not be able to work as leaders to see the full fledge program impacts. In Hungary, academic leadership positions can be held only until 65 years of age, and given the fact that the cycle of a B.A. is three years and and M.A. is minimum 2 this issue is fairly pressing. In our opinion, this generation gap is less discussed but potentially makes it very difficult to carry out proper research and high quality education (both for students and teachers). In Corvinus's case we can also state based on the external observations, that the department structure is very fragmented. The Faculty of Business Administration (FBA) started to merge these into "institutions" but in some cases the consolidation is a rather long process, for instance strategy is taught in three different departments which are in three different institutions. It is very difficult to create competitive research and innovation capability if critical mass of "scholarship" cannot be reached.

The composition of faculty is another problem to tackle, especially from the internationalization point of view. According to most international rankings business school faculty diversity is one of the most important criteria and all high ranked programs use a high variety of nationalities in their education. In case of Corvinus and of other universities in the region this is not only a financial and language question but very importantly a problem related to cultural openness The Hungarian academic tenure system is very closed, most universities hire their own Ph.D. graduates into the faculty, and academic faculty mobility is as rigid as other labor mobility in Hungary. Culturally, individuals are proud and rewarded for decades of institutional loyalty and although changing academic institution occurs, it is still quite rare. Therefore the historical bindings and very strong and rigid organizational cultures - quite often regionally limited - are major obstacles to embrace "foreign" ideas, change, and concretely individuals socialized in other organizational cultures.

The third major set of capability challenges are related to the development of resources enabling effective internationalization. To create a strong international presence, it is essential to maintain Corvinus University's leading position in Hungary and our presence in the alliances we are participating. Corvinus University's FBA is a CEMS member since 1996, PIM since 2002 and EFMD since 
2007. During the last decade these alliances ensured CUB's international recognition, but competition requires a new level of effort.

International accreditation is one requirement which is important to demonstrate quality which in return increases application and enrollment. However, not only the end result is important, but the entire process of accreditation which in case of Corvinus we see as a program for major change. Change to streamline administrative processes, research, program management and, most importantly how to create a common and excepted institutional strategy.

As far as global outreach is concerned the question is where to expand? In CEE, Asia or India? The ERASMUS is going well in the European continent but it is a "barter" exchange not providing extra revenues unless domestic intake can be increased. This is how we look at CEMS for instance; it is a vehicle to enhance local enrollment by offering attractive joint degrees. This on the other hand requires marketing strategy and sales, and this way the international alliances strengthen the domestic positions as well.

The final less obvious social challenge of the Bologna system is the spread of student quality and how it changes some traditional elements of student life in Hungarian institutions. Application quality is already showing a diversified picture. In 2008 around $90 \%$ of applicants to higher education have gotten admitted into a program even if it was not their first choice. This is a favorable social phenomena, however, the detailed statistics indicates two subtle but high impact challenges.

Firstly, there is a major difference between programs even within institutions. In 2008 the maximum admission points in Hungary were 480, there were 22 programs above 450, 10 of which are offered at Corvinus (including two above 460 which require outstanding high school graduation performance). These programs are all in the areas of business and management. There are close to 900 programs, however, which are in the range of 100-200 admission points which indicates that institutions also offer and run programs where selection level is very low. This would not be a problem itself, if these programs were evenly distributed among institutions and students would be "selected" after the first or second semesters. Our experience shows that this is not happening, institutions keep carrying admitted students, and high quality level applications significantly strengthen the bigger national institutions.

The second challenge of the application quality is the earlier mentioned high program fragmentation. At Corvinus for instance traditionally finance and accounting has been a demanding high level specialization, several key decision makers graduated from this area. In the pre-bologna system students had three years of foundations to decide to choose finance and accounting major and faculty on the other hand could select the most qualified and suitable candidates. In the 
bologna system finance and accounting is a self standing program with admission points about 40-50 point less than of the "popular" specializations. It is fearsome, that at Corvinus we keep loosing potentially very good finance and accounting students because of this "early" forced choice. It is true, that during the master level this might be remedied but still strategically it is important to maintain a strong capability and resource based advantage by keeping this specialization on a high level.

\section{SUMMARY}

In our paper, we wished to demonstrate how the business and economics higher education landscape has changed with the introduction of the Bologna programs. Corvinus University, as the consortium leader of universities and colleges implementing bologna programs, has collected insights and experiences on how the colleges influenced the Bologna program objectives, how the new entrants inflated the educational market, and how the competition intensified among traditional players for attracting students. We borrowed the fashionable long tail concept from the internet era, and used it for modeling the new landscape of internationalization of universities. Internationalization, mobility, and the appearance of the internet generation at the gates of our universities has brought us to the era which, appropriately we might as well call Education 2.0.

In our paper we first showed the characteristics of the long tail model of the Bologna based European higher education and potential messages for strategy making in this environment. We illustrated that benchmarking university strategies situated in the head of the long tail model will not always provide strategic guidance for universities sitting in the tail. Position is not a quality indicator in our opinion but rather related to the broad cultural and language environment, proximity to corporate headquarters; it is the issue of branding, funding and state policies as well. Universities in the tail should focus on niches, focused strategies building on the unique selling proposition in the Bologna-based ecosystem of student and faculty mobility.

For illustrating some key concerns in the Hungarian niche, we used Corvinus University as a case study to illustrate some untapped challenges of the Hungarian Bologna reform. We explored three areas which are crucial elements of the "tail" strategy in our opinion a) the influence of state regulation, b) social situations and impacts and c) internal university capabilities.

As we showed, educational reforms are highly political, and one key challenge is how to maneuver between the different stakeholders, and to keep the positive public image of higher educational at large and ensure parents, companies, politi- 
cal parties, local governments that the new system also will be beneficial for the society, that it keeps local values and mixes it properly with the influx of international influences through the enhanced mobility. The major political and social changes from the central political and economical system to the open market and democracy started close to 20 years ago in Hungary. Since then several waves of social transformation were undertaken by the population and the Bologna reform is embedded in these waves also therefore a careful understanding of the social consequences and environment is essential. In our case we wanted to show some less frequently mentioned fields such as the impact of mobility within regions, demographic implications, the balance between specialized and general education.

\section{REFERENCES}

Anderson, C. (2004): “The Long Tail”. Wired Magazine October 2004/12, 10; http://www. wired.com/wired/archive/12.10/tail.html.

Financial Times, Interactive European Business School Ranking; http://rankings.ft.com/ businessschoolrankings/european-business-school-rankings, retrieved: 2009-04-12.

Hrubos, I. (2006): A felsőoktatás intézményrendszerének átalakulása. Budapest: Aula.

Kerekes, S. - Nemeslaki, A. (2008): "The Hungarian Bologna Reforms in Business and Economics Education: Managing the Cracking Monopoly of Corvinus Universi”ty. In: Froment - Kohler Purser (eds): Bologna Handbook. Berlin: RAABE Academic Publishers. 